\section{The Structure of V214w from an Unidentified Fungus}

\author{
Deborah M. Roll*, Mark Tischler, \\ R. Thomas Williamson, and GuY T. CARTeR \\ Wyeth-Ayerst Research \\ Pearl River, New York 10965, U.S.A.
}

(Received for publication December 18, 2001)

While searching for novel biological activity during a recent reevaluation of samples from our Antibiotic Collection, we isolated the known antibiotic 6-epi-5'hydroxy-mycosporulone (1) ${ }^{1)}$ from culture V214, an unidentified mitosporic fungus (Fig. 1). From this same organism we now report the isolation and structure elucidation of a second metabolite, V214w (2).

Strain V214 was isolated from a soil sample collected from a sand dune along the Oregon coast. The organism was identified only as a member of the now obsolete order Sphaeropsidales. Pilot plant scale fermentation (300 liters) was carried out at $22^{\circ} \mathrm{C}$ for 94.5 hours. The production medium consisted of glucose $2.0 \%$, yeast extract $0.05 \%$, ammonium tartrate $0.2 \%, \mathrm{MgSO}_{4} \cdot 7 \mathrm{H}_{2} \mathrm{O} 0.05 \%, \mathrm{KH}_{2} \mathrm{PO}_{4}$
$0.1 \%, \mathrm{KCl} 0.05 \%$, and $\mathrm{FeSO}_{4} \cdot 7 \mathrm{H}_{2} \mathrm{O} 0.001 \%$, pH 6.5 . Sample extracts were periodically analyzed by TLC to insure that the desired metabolites had been produced.

The culture broth (290 liters, $\mathrm{pH}$ 5.2) was filtered and the filtrate was extracted with 200 liters of EtOAc. The organic layer (180 liters) was separated and concentrated in vacuo to $250 \mathrm{ml}$ of an oily residue. A $50 \mathrm{ml}$ portion weighing $\sim 56 \mathrm{~g}$ was subjected to silica gel chromatography $(6 \times 40$ $\mathrm{cm}$ column, 60 200 mesh), and was eluted under slight pressure at $25 \mathrm{ml} /$ minute using an eight liter gradient of $100 \%$ benzene to $5 \%$ EtOAc/benzene. One liter stepwise gradients of $10 \%, 25 \%$, and $50 \%$ EtOAc/benzene were then applied. A final three liter elution using EtOAc completed the process. Eighty milliliter fractions (170 total) were collected and analyzed by TLC for the desired metabolites. Fractions 126 135 were evaporated to give $7.3 \mathrm{~g}$ of V214x, identified as 1. Fractions $61 \sim 110$ were concentrated $(15 \mathrm{~g})$ and a $200 \mathrm{mg}$ portion was recrystallized to give $120 \mathrm{mg}$ of 2 as colorless rods.

The physicochemical properties of $\mathbf{2}$ are as follows: UV $\lambda_{\max }(\mathrm{MeOH}) \mathrm{nm}: 204$ (end absorption); IR $v_{\max }($ film) $\mathrm{cm}^{-1}$ : 3452, 3418, 2979, $1810(\mathrm{C}=\mathrm{O}), 1726(\mathrm{C}=\mathrm{O}), 1683$ $(\mathrm{C}=\mathrm{C})$, and 1134; $[\alpha]_{\mathrm{D}}^{25}=+100.6^{\circ}\left(c \quad 0.4, \mathrm{CHCl}_{3}\right) ; \mathrm{mp}$ $149 \sim 151{ }^{\circ} \mathrm{C}$; ${ }^{1} \mathrm{H}$ and ${ }^{13} \mathrm{C}$ NMR (Table 1); APCI-MS: pos $m / z 225(\mathrm{M}+\mathrm{H})^{+}$, neg $m / z 223(\mathrm{M}-\mathrm{H})^{-}$; HR ESI-MS: $(\mathrm{M}+\mathrm{H})^{+} m / z 225.07575$, calcd 225.07561 for $\mathrm{C}_{11} \mathrm{H}_{13} \mathrm{O}_{5}$.

Fig. 1. Structures of V214 metabolites.

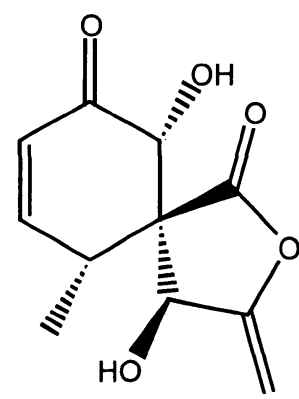

1

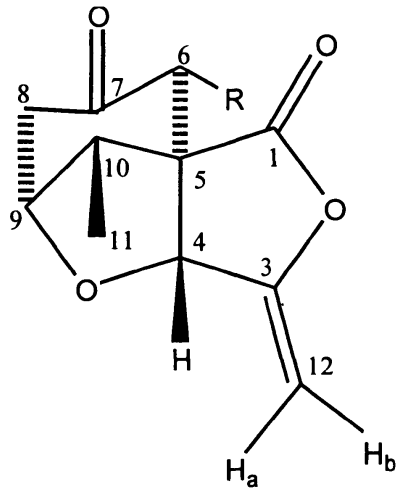

$2, \mathrm{R}=\mathrm{OH}$

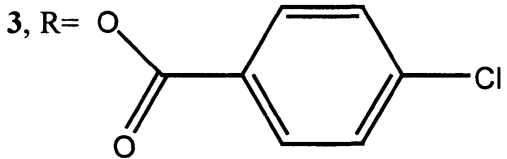

* Corresponding author: rolld@wyeth.com 
Table 1. ${ }^{1} \mathrm{H}$ and ${ }^{13} \mathrm{C}$ NMR shifts of $\mathbf{2}$ and $\mathbf{3}$.

\begin{tabular}{|c|c|c|c|c|}
\hline \multirow[b]{2}{*}{ Carbon } & \multicolumn{2}{|c|}{2} & \multicolumn{2}{|c|}{3} \\
\hline & $\delta_{\mathrm{C}}$ & $\delta_{\mathrm{H}}(\mathrm{mult}, J \mathrm{~Hz})$ & $\delta_{\mathrm{C}}$ & $\delta_{\mathrm{H}}(\mathrm{mult}, J \mathrm{~Hz})$ \\
\hline 1 & $168.8 \mathrm{~s}$ & & $167.8 \mathrm{~s}$ & \\
\hline 3 & $154.8 \mathrm{~s}$ & & $154.4 \mathrm{~s}$ & \\
\hline 4 & $78.0 \mathrm{~d}$ & $4.96(1 \mathrm{H}, \mathrm{t}, 1.9)$ & $78.9 \mathrm{~d}$ & $5.22(1 \mathrm{H}, \mathrm{s})$ \\
\hline 5 & $61.4 \mathrm{~s}$ & & $59.7 \mathrm{~s}$ & \\
\hline 6 & $76.1 \mathrm{~d}$ & $4.59(1 \mathrm{H}, \mathrm{br} \mathrm{s})$ & $76.2 \mathrm{~d}$ & $6.01(1 \mathrm{H}, \mathrm{s})$ \\
\hline $6-\mathrm{OH}$ & & $3.77(1 \mathrm{H}, \mathrm{br} \mathrm{s})$ & & \\
\hline 7 & $206.3 \mathrm{~s}$ & & $198.9 \mathrm{~s}$ & \\
\hline $8 a$ & $47.4 \mathrm{t}$ & $2.93(1 \mathrm{H}, \mathrm{dd}, 17.4,2.6)$ & $48.3 \mathrm{t}$ & $2.95(1 \mathrm{H}, \mathrm{d}, 17.5)$ \\
\hline $8 \mathrm{a}$ & & $2.60(1 \mathrm{H}, \mathrm{dt}, 17.4,2.6)$ & & $2.64(1 \mathrm{H}, \mathrm{d}, 17.5)$ \\
\hline 9 & $85.0 \mathrm{~d}$ & $4.48(1 \mathrm{H}, \mathrm{t}, 2.6)$ & $84.6 \mathrm{~d}$ & $4.53(1 \mathrm{H}, \mathrm{s})$ \\
\hline 10 & $45.5 \mathrm{~d}$ & $2.65(1 \mathrm{H}, \mathrm{q}, 7.1)$ & $46.5 \mathrm{~d}$ & $2.81(1 \mathrm{H}, \mathrm{q}, 6.8)$ \\
\hline 11 & $14.0 \mathrm{q}$ & $1.32(3 \mathrm{H}, \mathrm{d}, 7.1)$ & $14.1 \mathrm{~g}$ & $1.38(3 \mathrm{H}, \mathrm{d}, 6.8)$ \\
\hline $12_{\mathrm{a}}$ & $91.1 \mathrm{t}$ & $4.90(1 \mathrm{H}, \mathrm{t}, 3.0)$ & $91.7 \mathrm{t}$ & $4.98(1 \mathrm{H}, \mathrm{s})$ \\
\hline $12_{b}$ & & $4.63(1 \mathrm{H}, \mathrm{dd}, 3.0,3.0)$ & & $4.73(1 \mathrm{H}, \mathrm{s})$ \\
\hline 11 & & & $163.8 \mathrm{~s}$ & \\
\hline 2, & & & $127.0 \mathrm{~s}$ & \\
\hline $3^{\prime}, 7$ & & & $128.9 \mathrm{~d}$ & $7.42(2 \mathrm{H}, \mathrm{d}, 8.1)$ \\
\hline $4^{\prime}, 6$ ' & & & $131.3 \mathrm{~d}$ & $7.91(2 \mathrm{H}, \mathrm{d}, 8.1)$ \\
\hline 5 & & & $140.3 \mathrm{~s}$ & \\
\hline
\end{tabular}

$\delta$ from TMS in $\mathrm{CDCl}_{3}$

The molecular formula of 2 was established as $\mathrm{C}_{11} \mathrm{H}_{12} \mathrm{O}_{5}$ by HR ESI-MS and required six sites of unsaturation. Strong IR absorbances at 1810 and $1726 \mathrm{~cm}^{-1}$ indicated the presence of both ester (lactone) and saturated ketone carbonyl groups, while bands at 3452, 3418, and 1134 were indicative of hydroxyl and ether functionalities in the molecule. Eleven signals were well resolved in the ${ }^{13} \mathrm{C}$ NMR spectrum, presented in Table 1. Analysis of DEPT spectra accounted for one methyl, two methylene, four methine, and four quaternary carbons. Comparison with the formula suggested the presence of an additional hydroxyl group, which was seen as a broad singlet at $3.77 \mathrm{ppm}$ in the ${ }^{1} \mathrm{H}$ NMR spectrum. Carbon singlets at $\delta 206.3$ and $\delta 168.8$ were assigned to ketone and lactone carbonyl groups, respectively. Signals at $\delta 91.1(\mathrm{t})$ and $\delta 154.8$ (s) corresponded to an exomethylene group, as is found in $\mathbf{1}$ and the related metabolites rosigenin ${ }^{2)}$ and paecilospirone. ${ }^{3)}$ Compound 2 lacks the cis-olefin however, and to accommodate the degree of unsaturations in the molecular formula, it must be tricyclic.

Detailed analyses of 2D NMR experiments and comparison with data reported in the literature for similar compounds led to the structure of 2 . The similarity between V214w and other fungal metabolites containing a spirolactone skeleton was deduced from chemical shift values and $\mathrm{HMBC}$ connectivites, as shown in Fig. 2. Both exomethylene protons on $\mathrm{C}-12$ showed correlations to $\mathrm{C}-3$ at $154.8 \mathrm{ppm}$. The chemical shift value of $\mathrm{C}-3$ suggested that it was attached to oxygen. $\mathrm{H}-12_{\mathrm{a}}(\delta 4.90)$ also showed a correlation to C-4, and $\mathrm{H}-4$ in turn could be linked by three bond coupling to the cyclohexanone ring at C-6. H-6 displayed connections to the carbonyl at $\mathrm{C}-7$, quaternary carbon C-5, and C-4, and its chemical shift indicated that it was on a carbon bearing oxygen. Both methylene protons at C-8 showed correlations to the keto carbonyl group at C-7. In addition $\mathrm{H}_{\mathrm{a}}-8$ at $\delta 2.93$ displayed cross peaks to an oxygenated carbon at C-9 and a carbon bearing a methyl group at C-10. The proton on C-9 exhibited correlations to C-7, C-5, and C-4, while the hydrogen at C-10 afforded several linkages to C-4, C-5, C-6, C-8 and the C-11 methyl. Connectivites were observed from $\mathrm{H}-11$ to $\mathrm{C}-5, \mathrm{C}-9$, and $\mathrm{C}-$ 10. Very weak correlations were also noted from the hydroxyl proton at $\delta 3.77$ to $\mathrm{C}-5$ and C-7. However, no HMBC cross peaks were seen to the $\mathrm{C}-1$ lactone carbonyl at $\delta 168.8$. This problem was resolved by the preparation of a $p$-chlorobenzoate derivative, $\mathbf{3}$, which clearly showed a cross peak in the HMBC spectrum between $\mathrm{H}-6$ and $\mathrm{C}-1$. The physicochemical properties of 3 are: $\mathrm{UV} \lambda_{\max }\left(\mathrm{CH}_{3} \mathrm{CN} /\right.$ $\mathrm{HCOOH}) \mathrm{nm}: 242$; HR ESI-MS: $(\mathrm{M}+\mathrm{H})^{+} m / z 363.06300$, calcd 363.06317 for $\mathrm{C}_{18} \mathrm{H}_{16} \mathrm{ClO}_{6}$. 
Fig. 2. HMBC correlations of 2.

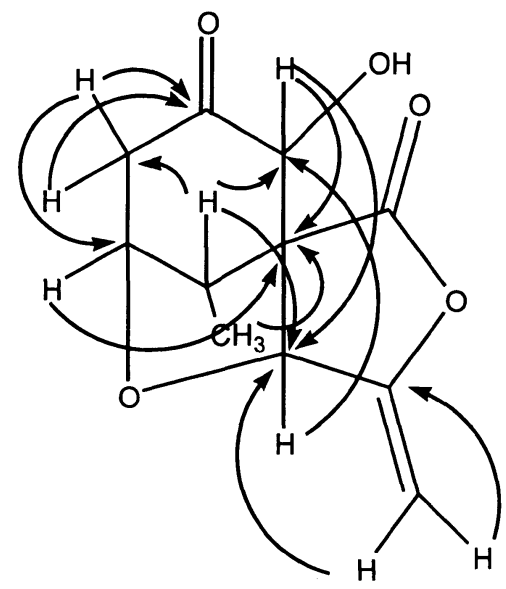

Analysis of the HMBC data permitted construction of partial structure a. Based on chemical shift values alone, there were potentially three sites for the placement of the hydroxyl group, although the HMBC data suggested that it should be attached at C-6. Evidence for the correct placement of the hydroxyl at C-6 rather than C-4 (as in related metabolites) came from a ${ }^{13} \mathrm{C}$ beta-isotope shift experiment, in which a carbon bearing a free hydroxyl that is exchanged with deuterium will show a small isotopic shift. The chemical shift of $\mathrm{C}-6$ measured in $\mathrm{CDCl}_{3}$ at $400 \mathrm{MHz}$ was $75.936 \mathrm{ppm}$. Addition of a drop of $d_{4}-\mathrm{MeOH}$ to the NMR tube and reacquisition of the carbon data showed an upfield shift for C-6 to $75.695 \mathrm{ppm}$ and broadening of the peak. No appreciable difference in chemical shift ( $\delta 77.886$ to $\delta 77.835$ ) or peak broadening was noted for C-4, supporting the HMBC data and assignment of the hydroxyl group to C-6. Formation of an ether linkage between $\mathrm{C}-4$ and $\mathrm{C}-9$ to give a tetrahydrofuran ring then satisfied the molecular formula and established the structure of $\mathbf{2}$ as shown.

The relative stereochemistry of V214w is supported by comparisons to related compounds having the spiro-lactone skeleton, correlations observed in the NOESY spectrum of 2, and ${ }^{1} \mathrm{H}-{ }^{1} \mathrm{H}$ coupling values. In order to form the tricyclic ring system, the five membered rings are positioned in a horizontal plane but are slightly puckered, while the cyclohexanone ring lies in a semi-chair conformation behind the plane. NOE correlations were noted between $\mathrm{H}$ 6 and $\mathrm{H}-10$, and also $\mathrm{H} 8_{\mathrm{b}}$ and $\mathrm{H}-9$. No other cross peaks were observed. This placed both the methyl and $\mathrm{OH}$ in a stable equitorial position, while $\mathrm{H}-6, \mathrm{H}-10$, and $\mathrm{H}-\mathrm{8}_{\mathrm{b}}$ are

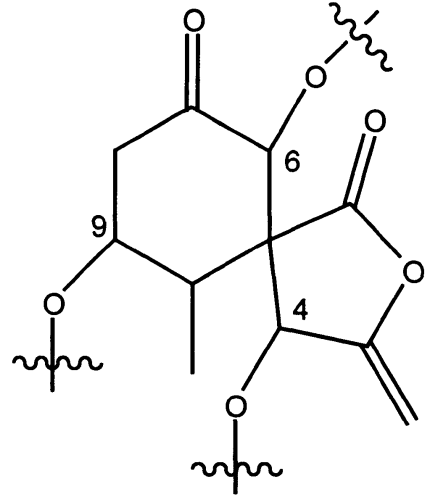

a

Fig. 3. Required 4-bond HMBC correlations of coniothyriol.

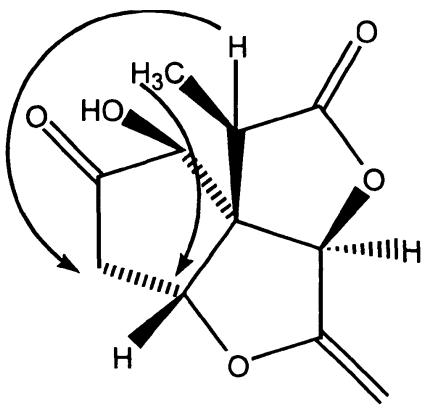

4

located in an axial orientation. The lack of vicinal coupling between methines $\mathrm{H}-9$ and $\mathrm{H}-10$ also support this configuration, and from a molecular model, the dihedral angle appears to be 90 degrees.

The 5,6 spiro-lactone ring has been reported in at least four other fungi. ${ }^{1 \sim 4)}$ One of these, Coniothyrium sporulosum, also produces a compound, coniothyriol (4), ${ }^{5)}$ which has the same molecular formula as 2 . The physicochemical data reported in the literature for $\mathbf{4}$ is very similar to what we report here. Some differences are apparent in the melting point, optical rotation, and IR values, but the NMR data is nearly identical. If structures 2 and 4 were to represent the same compound, then the HMBC data we observe would require three of the strong 
cross peaks ( $\delta \mathrm{H}_{2.65}$ to $\delta \mathrm{C}_{47.4}, \delta \mathrm{H}_{1.32}$ to $\delta \mathrm{C}_{85.0}$ in 2 , and $\delta$ $\mathrm{H}_{6.01}$ to $\delta \mathrm{C}_{167.8}$ in 3 ) to be four bond correlations in coniothyriol (Fig. 3). It seems likely that only a minor biosynthetic modification in 6-epi-5'-hydroxy-mycosporulone (1) would be needed to produce 2 , and that the proposed structure $\mathbf{2}$ is a better fit than $\mathbf{4}$ for the spectroscopic data which we have obtained.

V214w (2) has been tested in a number of therapeutic screens, but so far, has shown no interesting biological activity. The original antimicrobial activity noted for this culture has been attributed to $\mathbf{1}$.

\section{Acknowledgements}

We thank the Discovery Analytical Chemistry group for measurement of high resolution mass spectra.

\section{References}

1) Fukami, A.; Y. Taniguchi, T. Nakamura, M.-C. Rho, K. Kawaguchi, M. Hayashi, K. Komiyama \& S. Omura: New members of the macrosphelides from Microsphaeropsis sp. FO-5050 IV. J. Antibiotics 52: 501 504, 1999

2) Albinati, A.; S. Bruckner, L. Camarda \& G. Nasini: Rosigenin, an unusual metabolite from Mycosphaerella rosigena. Tetrahedron $36: 117 \sim 121,1980$

3) Hirota, A.; M. Nakagawa \& H. Hirota: Structure of paecilospirone, a new antibiotic from Paecilomyces. Agric. Biol. Chem. 55: 1187 1188, 1991

4) Kaouadi, M.; N. Buarque de Gusmao, R. Steiman \& F. Seigle-Murandi: Mycosporulone, a metabolite from Coniothyrium sporulosum. J. Nat. Prod. 56: 2189 2192, 1993

5) Buarque de Gusmao, N.; M. Kaouadi, R. Steiman, F. Seigle-Murandi \& J. Ulrich: Coniothyriol, an uncommon polyketide from Coniothyrium sporulosum. Nat. Prod. Lett. 2: 287 292, 1993 